\title{
Androgenetic Alopecia: a Review and Emerging Treatments
}

\author{
*Rubina Alves \\ Specialist in Dermatology, Department of Dermatology, Hospital Central do Funchal, Madeira, Portugal
}

Received: April 22, 2017; Accepted: June 09, 2017; Published: July 04, 2017

*Corresponding author: Rubina Alves, MD, PhD, Specialist of Dermatology, Universitat Internacional de Catalunya, Estrada Monumental, 364 3F, 9000-100 Funchal, Email: rubinaalves@gmail.com

\begin{abstract}
Androgenetic Alopecia (AGA) is the most common noncicatricial alopecia that leads to the progressive miniaturization of the hair follicle. Scalp terminal hairs are converted into vellus hairs, primarily due to two factors: genetic predisposition and hormonal stimulation.

The incidence and prevalence of AGA increases with age. The onset of AGA is gradual, and when this pathology progresses, the anagen phase shortens and the telogen phase remains constant. The shedding area varies from patient to patient and is usually most marked at the vertex in men, while women with AGA generally lose hair diffusely over the crown.
\end{abstract}

Topical minoxidil and oral finasteride (5-alpha-reductase type II inhibitor) are the gold-standard therapies for AGA and are currently the only Food and Drug Administration (FDA)-approved drugs for the treatment of AGA.

The currently available treatments for AGA are sometimes perceived as having limited effectiveness; therefore, the identification of new therapies for this pathology is of utmost importance.

This article aims to review the pathogenesis, diagnosis of AGA and all the new emerging treatments for this entity in order to prevent its progression and improve the results of this pathology.

Keywords: Androgenetic alopecia; Hair loss; Treatment; Minoxidil; Finasteride; Dutasteride; Low-level-laser therapy;

\section{Introduction}

Androgenetic Alopecia is a nonscarring alopecia that affects both men and women. It is characterized by a progressive miniaturization of hair follicles with a characteristic pattern distribution in genetically predisposed men and women [1]. Is the most frequent type of hair loss in both sexes [2-4].

The onset of AGA is usually gradual and the condition slowly develops over the years. The frequency and severity of this type of hair loss increases with age [5]. It usually appears in the third and fourth decades and affects $30 \%$ to $50 \%$ of men by the age of 50 and around $80 \%$ of caucasian men aged over 70 years $[1,2,6-$ 9].

As in men, the frequency and severity of Female Pattern Hair Loss (FPHL) increases with age [9]. According to Norwood [10], after examined a total of 1006 caucasian women, he found a prevalence of almost $30 \%$ in women over 30 years of age. Gan DC, et al. [8] reported that prevalence of mid-frontal hair loss also increases with age and affects $57 \%$ of women aged 80 and over.

The prevalence of AGA is different between populations; among asian, native american, and many men of african heritage is lower than that among caucasians with a decreased frequency of frontal hair loss and less extensive hair loss $[1,2,11]$.

Although AGA is more frequent in adults, it can also appear in adolescents, though its prevalence among this younger population is not well established [12,13]. On an average, adolescent AGA onset starts after puberty between 13.5 and 15 years of age [14]. Although it is not expected to see AGA in prepubertal patients without androgen levels $[15,16]$. Tosti, et al. [15] reported 20 prepubertal children with AGA with a very early onset age between 6 and 10 years. According to the authors, all patients had a strong genetic predisposition to the disease with a strong family history and the Dihydrotestosterone-Sulfatase (DHEA-S) levels were consistent with postadrenarche, but none of them was affected by premature puberty, as demonstrated by physical and laboratory assessments. In adolescents with a genetic predisposition, the first signs of AGA usually appear with rising androgens at puberty [17].

Beautiful and well-groomed hair represents youth, vitality and energy and is important in determining one's self-image and self-esteem [18]. In today's society, body image is influenced by many factors, such as the media and the fashion industry; and hair plays an important role. People who have thinning hair or any type of hair disease may feel unattractive and have a negative body image [19].

\section{Embryology and Normal Hair Development}

Hair follicles are derived from an interaction between the embryological ectoderm and mesoderm, which begins between 9 and 12 weeks of gestation. Human hair follicles primary develop in the regions of the eyebrows, upper lip and chin [20].

Then, hair follicles develop over the scalp in a frontal to occipital direction and progress over the body in a cephalocaudal 
direction [21]. On the trunk and limbs, the hair germ development is delayed and appears around the sixteenth week [22].

By 18-20 weeks of gestation, the entire initial population of follicles has formed, including those on the scalp, although follicular development is in different stages of evolution [23].

Human Follicles (HFs) develop through complex morphogenetic processes resulting from reciprocal molecular interactions between epithelium and underlying mesenchyme during embryonic development [24].

At birth, within anatomical regions and most of the scalp hair, all hairs are initially synchronous in anagen phase $[25,26]$ However, in the occipital scalp, telogen phase is delayed until after birth and this can give rise to a path of hair loss in this region of the scalp [27].

Initially, this Transient Neonatal Hair Loss (TNHL) also known as 'neonatal occipital alopecia' was thought to be secondary to friction due to babies sleeping in the supine position [20]. A prospective study was performed, and as stated by the authors, TNHL is related to the physiology of hair shaft shedding, it appears in healthy babies from birth until approximately the second month of life without accompanying symptoms and with spontaneous resolution [23].

Each follicle is capable of producing three different types of hair as follows: lanugo, vellus and terminal hairs. The initial hair produced is the lanugo hair. The type of hair originated by an individual follicle can change with age or under the influence of hormones [28].

Lanugo hair is nonmedullated, fine (typically less than $30 \mu \mathrm{m}$ in diameter), soft, and usually non pigmented hair which cover the whole body of the newborns [20]. Is typically shed between the thirty-second and thirty-six weeks of gestation, although it can remains by 3-4 months after birth in an unsynchronized wave pattern. Then he is replaced by vellus hair [12].

Vellus hair is short, light-colored, barely noticeable, and covers almost the whole body. Around puberty, there is an increase of the circulating adrenal androgens, which leads to a site-specific response from the hair follicles. With the presence of androgens, the hairs of the scalp miniaturize, while the hair of the body enlarges. At this time, the hairs of axillary, pubic, chest, and beard (boys) change from vellus to terminal hair, contributing to the development of the secondary sex characteristics $[21,28]$.

Terminal hair is larger (approximately 1 to $100 \mathrm{~cm}$ of length) and thicker usually with more than $60 \mu \mathrm{m}$ in diameter. This type of hair is strongly pigmented and is found on the scalp, eyebrows, axillary and pubic areas, chest and face [21]. In patients with AGA, terminal hairs follicles in the scalp convert to miniaturised hair follicles $(<30 \mu \mathrm{m}$ in diameter $)$.

\section{Anatomy and Hair cycle}

The hair follicle is anatomically divided into three parts: upper (infundibulum), middle (isthmus) and lower part (inferior segment). The infundibulum and isthmus comprise the permanent portions of the hair follicle and is a relatively constant structure, while the inferior segment is transient and undergoes cyclical regeneration [29]. A fourth segment of the pilosebaceous follicular unit would comprise the sebaceous gland [26].

In the permanent part, the infundibulum extends from the skin surface to the insertion of the sebaceous duct at the junction with the isthmus whereas the isthmus begins below the sebaceous duct and extends to the bulge or area of attachment for the arrector pili muscle [22].

The lower segment of the follicle is the site of the majority of activity in the hair follicle. Is comprised of three layers from outermost to innermost: Outer Root Sheath (ORS), Inner Root Sheath (IRS) and Hair Shaft (HS).

The inner part of hair bulb is invaginated at its base by the Dermal Papilla (DP). The IRS and HS are derived from epithelial cells surrounding the DP, a region known as the hair bulb matrix or germinative epithelium.

Dermal papilla size is dynamically regulated during the hair cycle [30]. Cells emigrate from the DP during catagen and then repopulate it in anagen $[31,32]$. The DP is a condensation of mesenchymal cells at the proximal end of the hair follicle, which determines hair shaft size and regulates matrix cell proliferation and differentiation. In large follicles the DP often contains a loop of capillary blood vessels. DP cells have the ability to regenerate new hair follicles. These cells tend to aggregate both in vitro and in vivo. This tendency is associated with the ability of papilla cells to induce hair growth [33]. The follicle miniaturization seen in AGA is thought to be driven by dysfunctional DP cell.

The human skin supports approximately 5 million hair follicles, of which approximately 100,000 are on the scalp [23].

Human hair grows in a continuous cyclic pattern presents with different phases: the anagen or growth phase, which lasts between 2 and 7 years, the catagen or regression phase, which has a duration of 2-3 weeks, the telogen phase, which lasts 3 months, and the shedding exogen phase [20].

The duration of hair cycle phases can be modulated by different physiological conditions in the same individual, in accordance with stages of postnatal, sexual development or seasonal environment [34]. The normal hair cycle results in the replacement of every hair on the scalp every 3-5 years [28].

The anagen phase receives signals from the cells of the germ to regenerate. The interface between the hair follicle epithelium and the mesenchyme increases progressively and the cells of the hair bulb matrix reproduce with a high mitotic rate and stem cells in the bulge give rise to hair germs to create a new $\mathrm{HF}[27,35]$.

When the period of active growth ends, the follicle growth stops and enters in a transitional physiological involution stage, the catagen phase. In catagen, bulbar portion of the follicle is 
degraded but HF stem cells are maintained in the bulge $[24,36]$. At this time, the follicle decreases in size as the DP cells move together [37]. After catagen, follicles undergo apoptosis and enter in the telogen phase. The hair filament remains in the telogen phase which later is detached during exogen [38].

The telogen or resting phase is followed by exogen in which the hair filament is detached.

The regenerative hair cycle is regulated by different molecular signals between follicular epithelium and mesenchymal DP cells [24]. The growth and development of HFs is influenced by a number of signals, different Growth Factors (GFs) and their receptors and cytokines. These signals also comprise transcription factors, nuclear receptors, neurotrophins and intracellular signaling pathways [27].

There is a balance of negative and positive influences regarding the activation or down-regulation of hair cycle and that is distinct for each phase of the hair cycle [39].

It has been described that anagen phase is activated by Wnt (wingless) / $\beta$-catenin (Beta-catenin) / LEFT (T-cell factor lymphoid enhancer), Sonic hedgehog (Shh) and the proteyoglican versican $[40,41,33]$. This molecules have been used as an indicator of hair inductiveness, many of which are also associated with aggregative behaviour.

Other GFs are involved in promoting the hair regrowth including Fibroblast Growth-Factor (FGF), Insulin-like Growth Factor 1 (IGF-1), Hepatocyte Growth Factor (HGF), Keratinocyte Growth Factor (KGF) and Vascular Endothelial Growth Factor (VEGF) [42-44,39]. This activation signalling leads to the stimulation of the hair germ in anagen phase.

The hair cycle is regulated through other pathways with a down-regulation affected, which are also essential for the proper hair formation. Others GFs exert their action through an inhibitory effect and down-regulation on hair growth and that may be involved in the beginning of the catagen phase [39]. Some of these GFs include: growth factor bone morphogenetic protein-4 (BMP4 ), transforming growth factor- $\beta$ (TGF- $\beta$ ), interleukin- $1 \alpha$ (IL-1 $\alpha$ ) and tumour necrosis factor- $\alpha$ (TNF- $\alpha)[45,46]$.

The knowledge of these molecular targets could help us to identify the potential therapeutic target of platelet-rich plasma, as described below.

\section{Pathophysiology of Androgenetic Alopecia}

The pathogenesis of AGA is influenced by two main factors: heredity and androgen action. AGA is considered a disease with a genetic predisposition, but the mode of inheritance has not been well characterized [47].

Inheritance is almost certainly polygenic, with genetic input from both parents. Studies performed on monozygotic twins showed strong concordance rates between 80 and $90 \%$, reinforcing the implication of a genetic basis $[12,48]$.
Family history predisposes to early development and rapid progression of the alopecia [3]. Its etiology is multifactorial and polygenetic $[1,49]$.

For the development of AGA, the presence of androgens, in combination with genetically susceptible hair follicles, is necessary [50].

The modulation of hair growth androgens is very important. Androgens such as testosterone are responsible for the conversion of vellus hair into terminal hairs of facial, trunk, extremities, pubic and axillary areas. The growths of these areas are similar in both sexes and begin around puberty. The growth of scalp hair is not dependent of the androgens, although it is well known they are necessary for the development of balding [51].

So, androgens will have a different effect regarding the location of the hair follicle. They are able to stimulate both the growth of hair (pubic, axilar, beard, chest) and also promote the loss of certain hair in the scalp, in genetical susceptible individuals.

TheandrogenhormonestestosteroneandDihydrotestosterone (DHT) each have selective roles at puberty. Testosterone is converted to DHT by the enzyme 5-alpha-reductase that has two isoenzymes: 5-alpha-reductase type I (present in the liver and sebaceous glands) and 5-alpha-reductase type II (present in the scalp, beard, chest, liver and prostate gland).

Testosterone is associated with increased muscle mass, growth of the scrotum, voice change, and the presence of terminal pubic and axillary hair fibers. An increased activity of 5-alphareductase type II plays an important role in the development of AGA; Levels of this isoenzyme are higher in men than in women and in the areas affected by AGA $[1,3]$.

DHT is associated with temporal scalp hair recession, acne, growth of the prostate gland, and the development of terminal hairs in the beard region, external ears, and limbs.

The hormone DHT activates the genes responsible for the shortening of hair growth cycle as well as the transformation of large hair follicles into smaller follicles that progressively become miniaturized [16].

AGA is characterized by the miniaturization of the hair that only occurs in certain areas: the frontotemporal and vertex area in men and the crown region in women. These scalp regions are susceptible to the effects of androgens. During the gradual transformation of the miniaturized follicles (from terminal to vellus-like follicles), the anagen phase shortens, and for this reason more hairs are in telogen phase [50]. There is no loss of hair follicles in AGA, just miniaturized [12]. DHT has been shown to inhibit hair growth in mouse models through blocking the actions of growth factors such as insulin-like growth factor 1 (IGF-1) [37,52].

\section{Diagnosis of Androgenetic Alopecia}

Most patients with AGA will be easily diagnosed by a clinical 
history and clinical examination, according to the condition of the characteristic distribution pattern [53]. Male pattern baldness is characterized by a receding hairline at the temples and balding of the vertex, which gradually enlarges to link together. In the female pattern, there is a diffuse decrease in density over the crown of the head and the frontal hairline is preserved.

Some noninvasive techniques such as trichoscopy and hair pull test help to perform the correct diagnosis. In some cases, it might be necessary to do a more extensive examination using other diagnostic tools, such as scalp biopsy. A laboratory examination might be extremely useful in some patients, especially in women, to evaluate any associated diseases. Global photographies performed at baseline are helpful to compare the efficacy of the treatment, both for patient and physician.

In the presence of a patient with hair loss the first to perform is a detailed clinical history. The history should include all demographic data of the personal history of the patient including age, sex, age at the first manifestation and grade of evolution of the hair loss, through time.

The family history of AGA is important because of the role of genetics in this pathology. Although a positive family history is frequent, a negative family history of AGA does not exclude the diagnosis [1,54].

An exhaustive history of associated diseases, systemic alterations and drug history are of utmost importance, as there are different factors such as nutritional or endocrine diseases and drug intake that could precipitate or aggravate the severity of the hair loss. Several environmental factors such as exposure to ultraviolet radiation and smoking have been associated with the development of AGA, so these aggravating factors should also be considered when performing the clinical history of the patient [55-58].

In the physical examination, besides the scalp skin and hair it should also be evaluated the facial and body hair and the nails.

The skin of the scalp should be examined to exclude signs of erythema, scaling, inflammation and atrophy. Usually, in patients with AGA, the scalp skin has no alterations although some patients can present with a discrete erythema and scaling related with seborrheic dermatitis that can be an aggravating factor. Jang WS, et al. [47] in a retrospective review found that seborrheic dermatitis was the most common associated disease in male and female patients with AGA.

In patients with advanced AGA, the skin of the scalp becomes smooth and shiny but in some cases a discrete atrophy can be present [1]. Nevertheless, the presence of atrophy should alert to another type of alopecia such as scarring alopecia.

These signs would easily help differentiate AGA from other types of hair loss or infections.

Hair examination includes the hair of the scalp, facial and the whole body.
The scalp hair of patients with AGA is a miniaturized hair with variation of hair calibre, length and re growth. It follows a characteristic pattern of distribution, which is different between sexes. Male pattern is characterized by recession of hairline, frontotemporal and vertex areas while in the female pattern, there's usually a diffuse distribution of hair loss, more pronounced in frontal and mid scalp areas. Unlike in male pattern, the frontal hairline in women is typically preserved.

Although, these are the most frequent patterns in both genders, there are other types of pattern distribution which have specific classifications, such as Hamilton-Norwood scale for men and Ludwig for women, the most frequently used. The Classifications of AGA are described below.

The examination of the facial and body hair will give further information, regarding differential diagnosis or associated pathologies. The absence or reduced of eyebrows/ eyelashes may suggest a frontal fibrosing alopecia or Alopecia Areata (AA) [1]. Regarding body hair examination, an excessive hair growth could lead the physician to think in hypertrichosis or signs of hyperandrogenism such as hirsutism.

To analyse with more detail the hair scalp, some noninvasive diagnostic tools may be helpful.

A hair pull test, also known as "traction test" or "Sabouraud's sign" helps distinguishes between active and non-active hair loss from follicles. To perform this test, around 50-100 hairs are grasped between the index finger and thumb and then lifted proximally to distally, with gentle traction [20]. This procedure is repeated in different areas of the scalp: frontal, occipital and temporal regions. The hair pull test is considered positive if more than $10 \%$ of telogen hairs are released, this means that if the pull test has more than 5 or 6 hair indicates ongoing hair activity [54,59].

False positives can occur if the test is performed on a day in which hair has been washed. A positive hair pull test will indicate an active hair shedding. Hair pull test in positive in Telogen Effluvium (TE). In patients with AGA, the hair pull test is usually negative, with the exception of active periods when a moderate telogen hair shedding is present in a pattern distribution [1].

Trichoscopy is a noninvasive technique performed using a handheld dermoscopy or a digital video dermatoscopy system. The handle dermoscopy usually has a 10 -fold magnification of the skin surface while the video dermoscope, which is equipped with a software, will have the benefit of larger magnification (ranging from 10-70 fold) and the conversion of measurement results into a database Trichoscopy adds important information for establishing the correct diagnosis and it is also a useful tool for assessing disease activity and monitoring treatment efficacy $[18,60,61]$.

In AGA, trichoscopy will easily identify the abnormalities present in this type of alopecia. Male and female AGA share similar trichoscopic features. 
The most important trichoscopic feature is hair shaft thickness heterogeneity, which means the presence of hairs with different thickness such as thin, intermediate and thick hairs [61]. Other features include vellus hairs (decreased terminal to vellus hair ratio), predominance of HF units with single hairs, yellow dots (hair follicles filled with hyperkeratotic plugs), perifollicular discolouration, wavy hair and honeycomb pigmentation $[60,62]$.

The videodermoscope with an automatic digitalised system will add more information of the analysed images regarding hair parameters such as number of hairs (number of hairs $/ 0.65$ $\mathrm{cm} 2$ ), hair density ( $\mathrm{n}$ per $\mathrm{cm} 2$ ), terminal hair density (n per $\mathrm{cm} 2$ ), anagen and telogen hairs (\%) and anagen/telogen ratio. In patients with AGA, frontal hair density is decreased when compared with occipital areas and anagen/telogen ration is normal or decreased [1].

The trichogram is a quantitative technique that provides information on the ability of hair growth and its alterations. Although an useful technique, it requires prior training and is time consuming [63]. Usually is not a frequent diagnostic technique used for the diagnosis of AGA.

Usually, scalp biopsy is the standard technique for diagnosing different types of scarring alopecia [54]. In addition, scalp biopsy could give relevant information in difficult cases of non scarring alopecia, where the diagnosis of the type of alopecia is uncertain. In few cases, the diagnosis of AGA is not clear, such as alterations of the scalp suggestive of scarring alopecia or diffuse AA, and a scalp biopsy may be needed to obtain the final diagnosis [1].

The scalp biopsy should be performed with a cylindrical punch of 4 to $6 \mathrm{~mm}$ in diameter, in an area representative of the hair loss [26]. Biopsies taken with a smaller punch than $4 \mathrm{~mm}$ in diameter are not recommended as it would give less number of follicle units, and as the follicles are not always affected simultaneously by a such disease it would diminishes the probability of a correct diagnosis [26]. The biopsy specimen should include the entire follicular unit and reach into the subcutaneous tissue where normally are the bulbs of anagen hair follicles $[54,64]$.

According to Blume-Peytavi, et al. [1], it should be obtained two 4-mm punch biopsies in which 1 biopsy is for vertical sectioning and the other biopsy for horizontal sectioning.

A horizontal sectioning of the scalp biopsy specimen would give more quantitative and morphometric data and allowed a visualization of a larger number of follicles, diameter and grouping whereas the vertical section would provide more information about the length of the hair follicle and full dermal thickness and this was a diagnostic advantage, especially in scarring alopecia $[54,65,66]$. It remains uncertain if biopsies should be oriented horizontally or vertically [26].

Recently, DU X, et al. [66] published a systematic review metaanalysis to evaluate the value of horizontal sections compared to vertical sections in the diagnosis of alopecia and found "no significant difference exists between horizontal and vertical sectioning techniques in the diagnosis of alopecia", although more studies are needed.

In areas affected by AGA is possible to identify an increased number of miniaturized follicles, and a ratio telogen-vellus of < $3: 1$ when compared to a ratio telogen-vellus of $<7: 1$, in patients without AGA [1,67].

The main histologic features in AGA are slight perifollicular lymphohistiocytic infiltration with a perivascular degeneration of the lower one third of the connective tissue [68].

The examination of the nails can add important information and is important for the differential diagnosis of other types of alopecia. Nail abnormalities such as pitting can be present in AA and liquen planus. Patients with AGA typically don't have any alteration in nails.

In women, although the majority has a normal hormonal function, a careful evaluation regarding gynaecological history should be done to exclude hormonal dysregulations [1].

Regarding laboratory examination and according to Camacho and colleagues in their protocol, the most important laboratory tests to be considered are levels of free testosterone, $5-\alpha-D H T$, DHEA-S, 17-beta-hydroxyprogesterone, prolactin, delta-4androstenedione, sex-hormone-binding globulin (SHBG), 3 - $\alpha$-androstanediol glucuronidel and prostatic-specific antigen (PSA) in both, premenopausal (normal levels $\leqq 0.02 \mathrm{ng} / \mathrm{mL}$ ) and postmenopausal women (nL $\leqq 0.04 \mathrm{ng} / \mathrm{mL}$ ) [63].

The global photography of the scalp is a non-invasive and useful method for determining clinical changes in the patient over time in a standardized manner.

\section{Classifications of Androgenetic Alopecia}

There are several classifications that help to determine the degree of androgenetic alopecia for male and female patients. This allows staging the degree of alopecia at the time of diagnosis and control the evolution and response to the treatment.

For male pattern hair loss, the classification widely used is:

- Hamilton-Norwood Classification: the most widely classification used for MPHL [10]. There are seven stages of evolution, involving the frontotemporal area and evolution of hair loss to the vertex. There are absence of frontal hairline, however, in some cases, men develop diffuse thinning of the crown with retention of frontal hairline that resembles a female pattern observed in Ludwig Classification.

For female pattern hair loss, the most common classifications are:

Ludwig's Classification: divided into three progressive stages based on hair density: I - minimal alopecia; II - Moderated alopecia and III - severe alopecia [69].

Ebling's Classification: includes a five stage classification system for FAGA. The first two stages are the same as the Ludwig 
system. Type III includes the diffuse hair loss and the initial loss of hair from the frontotemporal hair line; Type IV besides the diffuse loss there's evidence of frontotemporal recession; type $\mathrm{V}$, appears like the male pattern of baldness (MPHL) with a there is complete loss of hair on the top of the scalp [70].

Olsen's Classification: classification proposed by Olsen with 3 degrees of severity. The main characteristic of this classification is the "christmas tree" distribution, with a frontal accentuation in a triangular [71].

Savin Scale: a recent classification scale of 8 levels similar to Hamilton-Norwood's classification with frontal and lateral views of the hair loss patterns, that uses a computer analysis based in "the density of hair by unit of area" [63].

\section{Treatment of Androgenetic Alopecia}

The treatment of androgenetic alopecia should be initiate as early as possible as untreated androgen-dependent alopecia progressively deteriorates [72].

There are several treatment options available for the treatment of hair loss, although currently, only topical minoxidil and oral finasteride have the approval of Food and Drug Administration (FDA) for the treatment of AGA.

\section{Minoxidil}

Initially, oral minoxidil was used to treat high blood pressure. As a side effect of the treatment was an increased hair growth. Since then, topical minoxidil has been used to treat hair loss [6].

The 2\% topical minoxidil received the approval by US-FDA for the treatment of AGA in male and female patients in 1998 and 2001, respectively.

The 5\% topical minoxidil was approved for the treatment of AGA in men, in 2007 and the $5 \%$ foam minoxidil in 2006 also for the treatment of AGA in men [49]. The 5\% solution and $5 \%$ foam are not licensed by the FDA for use in women, but it is commonly used off-label for this purpose [12].

Minoxidil is a pyrimidine derivate that needs to be converted to its active metabolite, minoxidil sulphate, to exert its action. Minoxidil is thought to promote hair regrowth through its ability to open ATP-potassium channels. Although the exact mechanism of action of minoxidil is not fully understood, minoxidil has vasodilatory, proliferative and anti-inflammatory effects [53].

There are different possible mechanisms in which minoxidil could act to induce hair regrowth.

VEGF is known to increase angiogenesis and also promote perifollicular vascularization, hair growth rates, and increased follicle and hair size [44]. An VEGF mRNA is strongly expressed in DP cells during anagen phase with a substantial decrease of expression during catagen and telogen phases Topical minoxidil on the hair follicle can increased the expression of VEGF mRNA, presented in the DP cells $[49,73,74]$.
Lachgar, et al. [73] performed a study to evaluate if minoxidil could affect the expression of VEGF. According to the authors, minoxidil caused an elevation of VEGF and should be consider an indirect inducer of angiogenesis through an up regulation of the expression of VEGF in DP cells, during the anagen phase.

Other effects of minoxidil to induce hair regrowth could be the activation of activation of cytoprotective prostaglandin synthase-1 and increased expression of HGF, both hair growth promoters $[49,74,75]$.

The literature has demonstrated that topical minoxidil is as an effective treatment for AGA by promoting hair growth Minoxidil is available in $2 \%$ and $5 \%$ solutions and it is used twice a day in doses of $1 \mathrm{~mL}$ [76].

Several studies have demonstrated that minoxidil applied twice a day is an effective treatment for AGA, in both men and women [5,49,77-81].

Olsen, et al. [79] performed a Randomized Clinical Trial (RCT) comparing the use of $5 \%$ topical minoxidil versus $2 \%$ topical minoxidil and placebo in the treatment of AGA in men. The authors refer that the men who used $5 \%$ topical minoxidil had an earlier response to treatment than those who used 2\% topical minoxidil. Both 2 and 5\% topical minoxidil solutions were well tolerated by the men without evidence of systemic effects.

Concerning the treatment of FPHL, either 2 or 5\% (used offlabel) topical minoxidil solution appears safe to use in women with AGA. The only additional risk of the $5 \%$ topical minoxidil solution over the $2 \%$ topical minoxidil solution reported was the higher incidence of facial hypertrichosis [9].

Recently, 5\% minoxidil foam has received specially attention because of the good compliance of the patient and as hydroalcohol-based vehicle with absence of propylene glycol, presented in minoxidil topical solutions.

Blume-Peytavi, et al. [82] performed a randomized, singleblind study of $5 \%$ minoxidil foam once daily versus $2 \%$ minoxidil solution twice daily to compare their efficacy and safety in the treatment of AGA in women. According to the authors, both treatments were equally effective for improving hair loss, although once daily $5 \%$ MTF was better tolerated (lower incidence of pruritus and dandruff) with greater aesthetic advantages in comparison with twice-daily $2 \%$ minoxidil solution.

Another study reported that 5\% minoxidil foam could be more convenient with a better compliance of the treatment and was not associated with greater side effects. The present article provides update and reliable information that $5 \%$ minoxidil foam is a very good option for women patients with hair loss [83].

Some clinicians prescribe minoxidil in combination with other active ingredients, such as tretinoin. Bazzano GS, et al. [84] studied the combination of topical tretinoin with minoxidil and found a terminal hair regrowth in $66 \%$ of the patients, after 1 year of treatment. Another study compared the efficacy of $5 \%$ 
minoxidil alone (twice-daily) versus the combination of $5 \%$ minoxidil solution and $0.01 \%$ tretinoin (once daily) for MPHL. In this randomized, double-blind trial, the authors reported that the efficacy and safety of both treatments appear to be equivalent, with no statistical differences between the two treatment groups [85].

To assess the efficacy the patient should wait at least 6 months before considering if the treatment is effective. To ensure the compliance of the patient to the treatment, the physician have to inform about the transitory hair shedding that occurs after 2 months of the beginning of the treatment. The main side effects reported with the use of minoxidil are hypertrichosis and contact dermatitis.

\section{Alpha Reductase Inhibitors}

There are two types of $5 \alpha$-reductase enzymes, which have to be considered. Type $15 \alpha$-reductase enzyme predominates in the sebaceous gland, liver, skin and scalp while type 2 predominantly is mainly present in the prostate and certain regions of terminal hairs The $5 \alpha$-reductase inhibitors regulate the transformation of testosterone to DHT in DP cells of the follicular units [49].

The main $5 \alpha$-reductase inhibitors are finasteride and dutasteride.

A daily oral dose of $1 \mathrm{mg}$ finasteride reduces scalp DHT by $64 \%$ and serum DHT by $68 \%$. Dutasteride can decrease serum DHT by more than $90 \%$, while finasteride decreases serum DHT by $70 \%[6]$.

Oral finasteride is a competitive and specific inhibitor of type $25 \alpha$-reductase. In men with AGA, the balding scalp contains miniaturized hair follicles and increased amounts of DHT if compared to the hairy scalp. The administration of finasteride decreases scalp and serum DHT concentrations in bald scalp and increases scalp testosterone, as stated by Dallob and colleagues [86].

Finasteride has been investigated extensively and it is widely accepted as one of the more effective therapies for AGA in men $[49,87]$.

Mella, et al. [88], published a systematic review to assess the efficacy and safety of finasteride therapy for AGA, when compared to placebo. The authors report that moderate-quality evidence of the studied articles showed that daily use of oral finasteride increases hair count and improves patient and investigator assessment of hair appearance.

Treatment with finasteride should be life-long as its interruption is followed by gradual hair loss, with return to the pre-treatment status within 1 year.

The optimal dose of finasteride for male AGA was identified as $1 \mathrm{mg} /$ day [63].

Regarding the use and of finasteride in women, its efficacy is not well-established and is used as an off-label treatment of 2.5-5mg/day [89-91]. Two RCT have demonstrated that the use of $1 \mathrm{mg}$ /day is not effective in women. Price VH, et al. [92] published a double-blind, placebo-controlled, randomized, multicenter study and reported that after 12 months of treatment with finasteride $1 \mathrm{mg}$ /day in postmenopausal women there was a decrease in hair count from baseline and that finasteride was not effective in improving hair loss [92,93].

Oral dutasteride is an $5 \alpha$-reductase inhibitors of both type 1 and 2 enzymes and is prescribed as an off-label treatment for AGA.

Although with few studies published until now, the use of dutasteride appears to be safe and efficacious in the treatment of patients with AGA $[94,95]$.

In a recently published clinical trial, Tsunemi, et al. [96] reported that patients who took $0.5 \mathrm{mg}$ of oral dutasteride once daily for 52 weeks improved the hair regrowth, at 26 and 52 weeks. Of notice, between weeks 26 and 52 the proportion of patients who improved from baseline increased, which means that the effects of dutasteride are still progressing and that dutasteride needs a longer follow-up. The present study reports that dutasteride exhibited long-term safety, tolerability and efficacy for male AGA.

Different studies compared dutasteride versus finasteride in order to assess its efficacy and safety.

In 2004, Olsen EA, et al. [97] performed study in which men with AGA were randomized to receive daily dutasteride $(0.05$, $0.1,0.5$, or $2.5 \mathrm{mg}$ ), finasteride ( $5 \mathrm{mg}$ ), or placebo. After 24 weeks of treatment, both dutasteride and finasteride were superior to placebo and the group of $2.5 \mathrm{mg}$ dutasteride had a statistical significant improvement when compared with $5 \mathrm{mg}$ finasteride.

Tsunemi, et al. [96] reported that $0.5 \mathrm{mg}$ of dutasteride exhibited long-term safety, tolerability and efficacy for male AGA. Another study performed by Boersma, et al. [98] reported that $0.15 \mathrm{mg}$ of oral dutasteride appears to be significantly more effective than $1.25 \mathrm{mg}$ of oral finasteride in women under 50 years of age.

Both finasteride and dutasteride are frequently prescribed as off-label treatments for women with AGA. These drugs cross the blood-brain barrier and might cause the feminisation of a male fetus, which means that they are contraindicated for use in women with child-bearing potential and during pregnancy (Pregnancy Category X) [6]. Thus, special attention is needed in fertile women of childbearing age, for whom contraceptive measures are obligatory [6].

\section{Antiandrogens}

Oral antiandrogen therapy such as cyproterone acetate, spironolactone or flutamide are used in the treatment of FPHL, although evidence of efficacy for any of these treatments is limited [49]. Oral antiandrogens are used in women and are contraindicated in men due to their feminizing action. 
Cyproterone Acetate (CA) is an androgen receptor blocker and potent progestin It has been in common usage for over 40 years in the treatment of hirsutism but the limited controlled trial evidence has shown little evidence of efficacy in FPHL.

The mechanism of action of CA is to block androgen receptors and decrease testosterone levels by suppressing luteinizing hormone and follicle-stimulating hormone release $[63,99]$. It seems that CA may be more effective in women with hyperandrogenism.

There are no dose-ranging studies, but most practitioners use CA 50 to $100 \mathrm{mg} /$ day from the fifth to the 15th day of the menstrual cycle for a 6-month period. The first 10 days of each menstrual cycle, then followed by $2 \mathrm{mg} / \mathrm{d}$ from the first day of the cycle to the 21st, with a week of rest, for 18 months [63]. In premenopausal women, oral contraceptives such as ethanol estradiol should be added as it stabilizes menstrual irregularities. For postmenopausal women, CA may be used continuously.

The side effects of CA are dose dependent and this medication is absolutely contraindicated in patients with liver disease. In addition, feminization of a male fetus may occur and so patients should be advised to cease the medication before conception. According to Camacho et al opinion', CA is the best treatment for the FPHL [63].

Spironolactone is a potassium-sparring diuretic, structurally related to aldosterone (antagonist) that acts as an anti-androgenic by reducing the levels of total testosterone and competitively blocking the androgen receptor in target tissues [99]. Its primary use is as a diuretic and antihypertensive. There are no controlled trials in FPHL.

The dosage range from $50 \mathrm{mg} /$ day to $200 \mathrm{mg}$ /day for at least 6 months. The beginning is made with a starting low dose of 50 $\mathrm{mg} /$ day and increasing the monthly dose by $50 \mathrm{mg}$ to a final dose of $200 \mathrm{mg} /$ day $[63,100]$.

Side effects are dose related and include menstrual irregularities (menorrhagia), postmenopausal bleeding, breast tenderness, hyperkalemia and fatigue. In healthy young women, the risk of hyperkalemia is very low, although check of the serum potassium levels should be performed periodically [63].

This drug is category $\mathrm{X}$ for pregnancy, as it has as the potential to feminize a male fetus.

Flutamide is a pure, nonsteroidal antiandrogen that acts by inhibiting androgen uptake and by inhibiting nuclear binding of androgen within the target tissue. It is the treatment of choice when hair loss and hirsutism are associated with each other [101]. The most severe side effect is hepatotoxicity. Other side effects described include lethargy, mood change, and loss of libido. Is also contraindicated in pregnancy and lactancy as it may cause feminization of the male fetus.

\section{Emerging treatments}

The currently available treatments for AGA are sometimes perceived as having limited effectiveness; therefore, the identification of new therapies for this pathology is of utmost importance [102,103]. New possible offline treatments for AGA, such as topical finasteride, injectable dutasteride, laser therapy and PRP, have recently emerged and have been claimed to have hair growth-promoting or anti-hair loss effects.

\section{Topical finasteride}

Topical finasteride is being investigated as a new treatment for AGA with fewer side effects than oral finasteride. According to Caserini, et al. [104], a daily application of a $0.25 \%$ solution of finasteride (doses of 100 and $200 \mu \mathrm{L}$ ) leads to the inhibition of scalp DHT and may minimize the untoward sexual side effects that are linked to systemic DHT reduction [6].

A RCT compared oral finasteride and topical finasteride in 45 male patients with AGA. Patients were randomized in two groups to receive 1) twice daily finasteride gel $1 \%$ preparation and placebo tablets 2) oral finasteride $1 \%$ and placebo gel, for 6 months [105]. According to the authors, the results showed similar efficacy for the two therapies, although not statistically significant.

A study conducted by Tanglertsampan C compared the safety and efficacy of $3 \%$ minoxidil solution (MNX) versus the combination of $3 \%$ minoxidil and $0.1 \%$ finasteride solution (MFX) in the treatment of men with AGA [106]. At 24 weeks, there was an increase of hair count from baseline in both groups, but no statistical difference. The assessment by global photography showed significantly greater improvement in the MFX group than the MNX group.

Another study assessed the efficacy of 5\% topical minoxidil fortified with $0.1 \%$ finasteride in patients with AGA who had been medicated with $5 \%$ topical minoxidil and oral finasteride in the previous two years [107]. The aim was to assess the efficacy of maintaining the hair growth. Eighty-four percent maintained a good hair density after 12 months of treatment with minoxidilfinasteride combination.

There are few published articles regarding topical finasteride and usually topical finasteride is used in combination with other medication. At this moment, there is insufficient evidence to support the use of topical finasteride [49]. Additional studies using the topical finasteride alone are needed to assess its efficacy.

\section{Injectable dutasteride}

Injectable dutasteride might be a promising treatment for AGA. In 2013, Moftah, et al. [108] published a study that evaluated the efficacy and safety of mesotherapy using a dutasteride-containing preparation $(0.5 \mathrm{mg}$ of dutasteride, 20 $\mathrm{mg}$ of biotin, $200 \mathrm{mg}$ of pyridoxin and $500 \mathrm{mg}$ of D-panthenol) in female patients with hair loss. The authors concluded that this preparation was effective, tolerable and yielded better response among females with a shorter duration of disease. More studies 
are needed with the use of injectable dutasteride alone, to assess its efficacy.

\section{Low-level laser therapy}

The laser therapy is the application of Light of Low-Level Laser (LLL) or Laser-Emitting Diodes (LED) with a spectral of $600-1000 \mathrm{~nm}$ and is used to treat several conditions such as pain reduction, inflammation and to promote wound healing and tissue regeneration $[109,110]$. Recently, it has been use to promote hair regrowth. For its used in hair loss, most of the available devices use a wavelength of $655 \mathrm{~nm}$.

The first LLLT device, the Hairmax Lasercomb® was approved by the US FDA and received clearance as a safe therapy for the treatment of male AGA in 2007 and female AGA in 2011 $[111,112]$.

Although the exact mechanism of LLLT is not clear, this laser phototherapy might induce proliferation, migration, oxygenation and stimulate the transition from telogen hair follicles to anagen $[110,111,113]$.

A systematic review was carrying out and found and the majority of studies covered in the review found an overall improvement in hair regrowth, thickness, and patient satisfaction following LLLT therapy [114].

Another evidence-based review stated that LLLT devices are both safe and effective for the treatment of FPHL and MPHL [113].

Avram MR, et al. [115] performed a study in 7 patients to investigate the efficacy of LLLT in hair regrowth and found a not statistical significance decrease in the number of vellus hairs, an increase in the number of terminal hairs, and an increase in shaft diameter. No improvement in hair density was noted.

Although published articles found that LLLT could improve hair regrowth, the LLLT results are limited with a low number of patients. More studies, including RCT are needed to support its efficacy. In addition, the optimum dose, wavelength, coherence and dosimetric parameters remain to be determined $[113,116,117,110]$.

As stated by Gupta AK, et al. [110], clinical studies should be conducted and published in peer-reviewed journals and although manufacturers believe in the quality and efficacy of their device, this might not be "sufficient for physicians to accept LLLT for hair loss and widely promote it, without reservation, to patients".

\section{Prognosis of Androgenetic Alopecia}

There have been a number of studies regarding a relationship between AGA and associated diseases, such as hypertension, hyperlipidemia, diabetes mellitus, and Coronary Artery Disease (CAD).

Ahouansou, et al. [118] evaluated the association between AGA and hypertension and found that men, aged between 19 to 50 years and who have early AGA (occurring before 35 years of age), had an increased incidence of hyperinsulinemia and disorders associated with insulin resistance, such as obesity, hypertension, and dyslipidemia $[47,119]$.

Patients with AGA might be at an increased risk of CAD which increases with increasing grade of AGA [120].

Arias-Santiago, et al. [121] performed a case control study with 154 participants, to analyze the presence of the cardiovascular risk factors and the prevalence of carotid atheromatosis in male and female patients with AGA in comparison with control subjects. According to author's results, the metabolic syndrome was diagnosed in $60 \%$ and $48.6 \%$ of male and female patients with AGA, respectively; Atheromatous plaques were more frequent in patients with AGA than in controls and that was statistical significant.

Therefore, the determination of metabolic syndrome, ultrasound study of the carotid arteries in patients with AGA may be useful screening methods to detect risk of developing cardiovascular disease in patients with early-onset AGA and signal a potential opportunity for early preventive treatment.

\section{References}

1. Blume-Peytavi U, Blumeyer A, Tosti A, Finner A, Marmol V, Trakatelli M, et al. European Consensus Group. S1 guideline for diagnostic evaluation in androgenetic alopecia in men, women and adolescents. Br J Dermatol. 2011;164(1):5-15. doi: 10.1111/j.13652133.2010.10011.x

2. Paik JH, Yoon JB, Sim WY, Kim BS, Kim NI. The prevalence and types of androgenetic alopecia in Korean men and women. $\mathrm{Br}$ J Dermatol. 2001;145(1):95-99.

3. Tosti A, Piraccini BM. Androgenetic alopecia. Int J Dermatol. 1999;38 Suppl 1:1-7.

4. Paus R, Olsen EA, Messenger AG. Hair growth disorders. In: Fitzpatrick, Dermatology in General Medicine, Ed Panamericana. 2009:225-243.

5. Krupa Shankar D, Chakravarthi M, Shilpakar R. Male androgenetic alopecia: population-based study in 1,005 subjects. Int J Trichology. 2009;1(2):131-133. doi: 10.4103/0974-7753.58556

6. Cranwell W, Sinclair R. Male Androgenetic Alopecia. 2016 Feb 29. In: De Groot LJ, Chrousos G, Dungan K, Feingold KR, Grossman A, Hershman JM, Koch C, Korbonits M, McLachlan R, New M, Purnell J, Rebar R, Singer F, Vinik A, editors. Endotext [Internet]. South Dartmouth (MA): MDText.com, Inc. 2000

7. Rathnayake D, Sinclair R. Male androgenetic alopecia. Expert Opin Pharmacother. 2010;11(8):1295-1304

8. Gan DC, Sinclair RD. Prevalence of male and female pattern hair loss in Maryborough. J Investig Dermatol Symp Proc. 2005;10(3):184-189.

9. Olsen EA, Messenger AG, Shapiro J, Bergfeld WF, Hordinsky MK, Roberts JL, et al. Evaluation and treatment of male and female pattern hair loss. J Am Acad Dermatol. 2005;52(2):301-311.

10.Norwood OT. Incidence of female androgenetic alopecia (female pattern alopecia). Dermatol Surg. 2001;27(1):53-54. 
11.Setty LR. Hair patterns of the scalp of white and Negro males. Am J Phys Antropol. 1970;33(1):49-55.

12.Alves R, Grimalt R. Androgenetic Alopecia in Adolescents. In: Oranje AP, Al-Mutairi N, Shwayder T (Eds.). Practical Pediatric Dermatology. Controversies in Diagnosis and Treatment. Switzerland: Springer. 2016;187-196.

13.Kim BJ, Kim JY, Eun HC, Kwon OS, Kim MN, Ro BI. Androgenetic alopecia in adolescents: a report of 43 cases. J Dermatol. 2006;33(10):696-699.

14.McDonough PH, Schwartz RA. Adolescent androgenic alopecia. Cutis. 2011;88(4):165-168.

15.Tosti A, Iorizzo M, Piraccini BM. Androgenetic alopecia in children: report of 20 cases. Br J Dermatol. 2005;152(3):556-559.

16.Price VH. Androgenetic alopecia in adolescents. Cutis. 2003;71(2):115121.

17.Gonzalez ME, Cantatore-Francis J, Orlow SJ. Androgenetic alopecia in the paediatric population: a retrospective review of 57 patients. Br J Dermatol. 2010;163(2):378-385. doi: 10.1111/j.13652133.2010.09777.x

18.Alves R. PRP in Alopecia. In: Alves R, Grimalt R, editor. Clinical indications and treatment protocols with Platelet-rich plasma in Dermatology. Barcelona:Ediciones Mayo; 2016. P. 29-44.

19.Budd D, Himmelberger D, Rhodes T, Cash TE, Girman CJ. The effects of hair loss in European men: a survey in four countries. Eur J Dermatol. 2000;10(2):122-127.

20.Alves R, Grimalt R. Hair loss in children. Curr Probl Dermatol. 2015;47:55-66. doi: 10.1159/000369405

21.Moreno-Romero JA, Grimalt R. Hair loss in infancy. G Ital Dermatol Venereol. 2014;149(1):55-78.

22.Abell Edward. Embryology and anatomy of the hair follicle. In: Olsen EA, editor. Disorders of hair growth. Diagnosis and treatment. 2nd ed. New York:McGraw Hill; 1994.p.1-17.

23.Cutrone M, Grimalt R. Transient neonatal hair loss: a common transient neonatal dermatosis. Eur J Pediatr 2005;164(10):630-632.

24.Chueh SC, Lin SJ, Chen CC, Lei M, Wang LM, Widelitz R, et al. Therapeutic strategy for hair regeneration: hair cycle activation,niche environment modulation, wound-induced follicle neogenesis, and stem cell engineering. Expert Opin Biol Ther. 2013;13(3):377-391. doi: $10.1517 / 14712598.2013 .739601$

25.Olsen EA. Hair loss in childhood. In: Olsen EA, editor. Disorders of hair growth. Diagnosis and treatment. 2nd ed. New York: McGraw Hill; 1994. p. 177-238.

26.Olsen EA. Clinical tools for assessing hair loss. In: Olsen EA, editor. Disorders of hair growth. Diagnosis and treatment. 2nd ed. New York: McGraw Hill; 1994. p. 59-69.

27.Messenger AG, Berker DAR, Sinclair RD. Disorders of Hair. In: Burns DA, Breathnach SM, Cox NH, Griffiths CEM, editor. Rook's Textbook of Dermatology, 8th edition. Blackwell Publishing Ltd; 2010. p. 66.166.16 .

28.Harrison S, Sinclair R. Optimal management of hair loss (alopecia) in children. Am J Clin Dermatol. 2003;4(11):757-770.
29.Shapiro R, et al. Hair anatomy and histology. In: Unger WP, Shapiro R. Hair transplantation. 4th ed. Revised and expanded; Marcel Dekker, New York: 2004. p. 25-33.

30.Rufaut NW, Nixon AJ, Goldthorpe NT, Wallace OA, Pearson AJ, Sinclair RD. An in vitro model for the morphogenesis of hair follicle dermal papillae. J Invest Dermatol. 2013;133(8):2085-2088.

31.Tobin DJ, Gunin A, Magerl M, Handijski B, Paus R. Plasticity and cytokinetic dynamics of the hair follicle mesenchyme: implications for hair growth control. J Invest Dermatol. 2003;120(6):895-904.

32.Chi WY, Enshell-Seijffers D, Morgan BA. De novo production of dermal papilla cells during the anagen phase of the hair cycle. J Invest Dermatol. 2010;130(11):2664-2666. doi: 10.1038/jid.2010.176

33.Sari AR, Rufaut NW, Jones LN, Sinclair RD. Characterization of ovine dermal papilla cell aggregation. Int J Trichology. 2016;8(3):121-129. doi: 10.4103/0974-7753.188966.

34.Chuong CM, Randall VA, Widelitz RB, Wu P, Jiang TX. Physiological regeneration of skin appendages and implications for regenerative medicine. Physiology (Bethesda). 2012;27(2):61-72. doi: 10.1152/ physiol.00028.2011

35.Montagna W, Camacho F. Embriología y anatomia del foliculo piloso. Ciclos de crecimiento del pelo. In: Camacho FM, Tosti A (Eds), 3rd Edition. Tricología: enfermedades del folículo pilosebáceo. Madrid: Grupo Aula Médica; 2013. p.1-38.

36.Stenn KS, Paus R. Controls of hair follicle cycling. Physiol Rev. 2001;81(1):449-494.

37.Gupta AK, Carviel J. A Mechanistic Model of Platelet-Rich Plasma Treatment for Androgenetic Alopecia. Dermatol Surg. 2016;42(12):1335-1339.

38. Sinclair RD, Banfield CC, Dawber RPR. Hair structure and function. In: Sinclair RD, Banfield CC, Dawber RPR (Eds). Handbook of diseases of the hair and scalp. Oxford: Blackwell Science; 1999. p. 3-10.

39.Botchkarev VA, Kishimoto J. Molecular control of epithelialmesenchymal interactions during hair follicle cycling. J Investig Dermatol Symp Proc. 2003;8(1):46-55.

40. Myung PS, Takeo M, Ito M, Atit RP. Epithelial Wnt ligand secretion is required for adult hair follicle growth and regeneration. J Invest Dermatol. 2013;133(1):31-41. doi: 10.1038/jid.2012.230

41. Woo WM, Zhen HH, Oro AE. Shh maintains dermal papilla identity and hair morphogenesis via a Noggin-Shh regulatory loop. Genes Dev. 2012;26(11):1235-1246. doi: 10.1101/gad.187401.112

42. Hodak E, Gottlieb AB, Anzilotti M, Krueger JG. The insulin-like growth factor 1 receptor is expressed by epithelial cells with proliferative potential in human epidermis and skin appendages: correlation of increased expression with epidermal hyperplasia. J Invest Dermatol. 1996;106(3):564-570.

43. Philpott MP, Sanders DA, Kealey T. Effects of insulin and insulin-like growth factors on cultured human hair follicles: IGF-I at physiologic concentrations is an important regulator of hair follicle growth in vitro. J Invest Dermatol. 1994;102(6):857-861.

44. Yano K, Brown LF, Detmar M. Control of hair growth and follicle size by VEGF- mediated angiogenesis. J Clin Invest. 2001;107(4):409-417. 
45. Hu HM, Zhang SB, Lei XH, Deng ZL, Guo WX, Qiu ZF, et al. Estrogen leads to reversible hair cycle retardation through inducing premature catagen and maintaining telogen. PLoS One. 2012;7(7):e40124. doi: 10.1371/journal.pone.0040124

46. Foitzik K, Lindner G, Mueller-Roever S, Maurer M, Botchkareva N, Botchkarev V, et al. Control of murine hair follicle regression (catagen) by TGF-beta1 in vivo. FASEB J. 2000;14(5):752-760.

47.Jang WS, Son IP, Yeo IK, Park KY, Li K, Kim BJ, et al. The annual changes of clinical manifestation of androgenetic alopecia clinic in korean males and females: a outpatient-based study. Ann Dermatol. 2013;25(2):181-188. doi: 10.5021/ad.2013.25.2.181

48. Chumlea WC, Rhodes T, Girman CJ, Johnson-Levonas A, Lilly FR, Wu R, et al. Family history and risk of hair loss. Dermatology. 2004;209(1):3339.

49. Blumeyer A, Tosti A, Messenger A, Reygagne P, Del Marmol V, Spuls PI, et al. European Dermatology Forum (EDF). Evidence-based (S3) guideline for the treatment of androgenetic alopecia in women and in men.J Dtsch Dermatol Ges. 2011;9 Suppl 6:S1-57. doi: 10.1111/j.16100379.2011.07802.x

50. Kaufman KD. Androgen metabolism as it affects hair growth in androgenetic alopecia. Dermatol Clin. 1996;14(4):697-711.

51. Messenger AG. The control of hair growth and pigmentation; In: Olsen EA, editor. Disorders of hair growth. Diagnosis and treatment. 2nd ed. New York: McGraw Hill; 1994. p. 39-58.

52.Zhao J, Harada N, Okajima K. Dihydrotestosterone inhibits hair growth in mice by inhibiting insulin-like growth factor-I production in dermal papillae. Growth Horm IGF Res. 2011;21(5):260-267. doi: 10.1016/j. ghir.2011.07.003

53. Torres F. Androgenetic, diffuse and senescent alopecia in men: practical evaluation and management. Curr Probl Dermatol. 2015;47:33-44. doi: $10.1159 / 000369403$

54. Mubki T, Rudnicka L, Olszewska M, Shapiro J. Evaluation and diagnosis of the hair loss patient: part I. History and clinical examination. J Am Acad Dermatol. 2014;71(3):415.e1-415.e15. doi: 10.1016/j. jaad.2014.04.070

55.Camacho F, Moreno JC, Garcia-Hernandez MJ. Telogen alopecia from UV rays. Arch Dermatol 1996;132:1398-1399. doi:10.1001/ archderm.1996.03890350142037

56.Trüeb RM. Is androgenetic alopecia a photoaggravated dermatosis? Dermatology. 2003;207(4):343-348.

57. Su LH, Chen TH. Association of androgenetic alopecia with smoking and its prevalence among Asian men: a community-based survey. Arch Dermatol 2007;143:1401-1406.

58. Trüeb RM. Association between smoking and hair loss: another opportunity for health education against smoking? Dermatology. 2003;206(3):189-191.

59. Tosti A, Gray J. Assessment of hair and scalp disorders. J Investig Dermatol Symp Proc. 2007;12(2):23-27.

60. Rudnicka L, Olszewska M, Rakowska A, Kowalska-Oledzka E, Slowinska M. Trichoscopy: a new method for diagnosing hair loss. J Drugs Dermatol. 2008;7(7):651-654.
61. Mubki T, Rudnicka L, Olszewska M, Shapiro J. Evaluation and diagnosis of the hair loss patient: part II. Trichoscopic and laboratory evaluations. J Am Acad Dermatol. 2014;71(3):431.e1-431.e11. doi: 10.1016/j.jaad.2014.05.008

62. Rakowska et al. Androgenetic Alopecia. In: Atlas of Trichoscopy. Rudnika L, Olszewska, Rakowska, (editor). London: Springer-Verlag; 2012. p. 221-35.

63. Camacho-Martınez FM. Hair loss in women. Semin Cutan Med Surg. 2009;28(1):19-32. doi: 10.1016/j.sder.2009.01.001

64. Whiting DA. Diagnostic and predictive value of horizontal sections of scalp biopsy specimens in male pattern androgenetic alopecia. J Am Acad Dermatol. 1993;28(5 Pt 1):755-763.

65. Ozcan D, Ozen 0, Seckin D. Vertical vs. transverse sections of scalp biopsy specimens: a pilot study on the comparison of the diagnostic value of two techniques in alopecia. Clin Exp Dermatol. 2011;36(8):855-863. doi: 10.1111/j.1365-2230.2011.04154.x

66. Du X, Li Z, Xu W, Zhou X, Tang S, Song C, et al. Diagnostic value of horizontal versus vertical sections for scarring and non-scarring alopecia: a systematic review and meta-analysis. Eur J Dermatol. 2016;26(4):361-369.

67. Dhurat R, Saraogi P. Hair evaluation methods: merits and demerits. Int J Trichology. 2009;1(2):108-119. doi: 10.4103/0974-7753.58553

68. Olsen EA. Androgenetic alopecia. In: Olsen EA, editor. Disorders of hair growth. Diagnosis and treatment. 2nd ed. New York: McGraw Hill; 1994. p. 257-283.

69. Ludwig E: Classification of the types of androgenetic alopecia (common baldness) occurring in the female sex. Br J Dermatol 1977;97(3):247254.

70. Gupta M, Mysore V. Classifications of Patterned Hair Loss: A Review. J Cutan Aesthet Surg. 2016;9(1):3-12. doi: 10.4103/0974-2077.178536

71. Olsen EA, Hordinsky M, Roberts JL, Whiting DA; Dermatologic Consortium for Women's Health. Female pattern hair loss. J Am Acad Dermatol. 2002;47(5):795.

72. Rushton DH, Ramsay ID, Norris MJ, Gilkes JJ. Natural progression of male pattern baldness in young men. Clin Exp Dermatol. 1991;16(3):188-192.

73. Lachgar S, Charveron M, Gall Y, Bonafe JL. Minoxidil upregulates the expression of vascular endothelial growth factor in human hair dermal papilla cells. Br J Dermatol. 1998;138(3):407-411.

74. Kaliyadan F, Nambiar A, Vijayaraghavan S. Androgenetic alopecia: An update. Indian J Dermatol Venereol Leprol. 2013;79(5):613-625. doi: 10.4103/0378-6323.116730

75. Jain R, De-Eknamkul W. Potential targets in the discovery of new hair growth promoters for androgenic alopecia. Expert Opin Ther Targets. 2014;18(7):787-806. doi: 10.1517/14728222.2014.922956

76. Kanti V, Hillmann K, Kottner J, Stroux A, Canfield D, Blume-Peytavi U. Effect of minoxidil topical foam on frontotemporal and vertex androgenetic alopecia in men: a 104-week open-label clinical trial. J Eur Acad Dermatol Venereol. 2016;30(7):1183-1189. doi: 10.1111/ jdv.13324

77. Alanis A, Barbara F, Meurehg C, De Oca FL, Ramirez L. Double-blind 
comparison of $2 \%$ topical minoxidil and placebo in early male pattern baldness. Curr Ther Res Clin Exp. 1991;49(5):723-730.

78. Van Zuuren EJ, Fedorowicz Z, Carter B. Evidence-based treatments for female pattern hair loss: a summary of a Cochrane systematic review. Br J Dermatol. 2012;167(5):995-1010. doi: 10.1111/j.13652133.2012.11166.x

79. Olsen EA, Dunlap FE, Funicella T, Koperski JA, Swinehart JM, Tschen $\mathrm{EH}$, et al. A randomized clinical trial of $5 \%$ topical minoxidil versus $2 \%$ topical minoxidil and placebo in the treatment of androgenetic alopecia in men. J Am Acad Dermatol. 2002;47(3):377-385.

80. Lucky AW, Piacquadio DJ, Ditre CM, Dunlap F, Kantor I, Pandya AG, et al. A randomized, placebo-controlled trial of $5 \%$ and $2 \%$ topical minoxidil solutions in the treatment of female pattern hair loss. J Am Acad Dermatol. 2004;50(4):541-553.

81. Price VH, Menefee E, Strauss PC. Changes in hair weight and hair count in men with androgenetic alopecia, after application of $5 \%$ and 296 topical minoxidil, placebo, or no treatment. J Am Acad Dermatol. 1999;41(5 Pt 1):717-721.

82. Blume-Peytavi U, Hillmann K, Dietz E, Canfield D, Garcia Bartels N. A randomized, single-blind trial of $5 \%$ minoxidil foam once daily versus $2 \%$ minoxidil solution twice daily in the treatment of androgenetic alopecia in women. J Am Acad Dermatol. 2011;65(6):1126-1134.e2. doi: 10.1016/j.jaad.2010.09.724

83. Blume-Peytavi U, Shapiro J, Messenger AG, Hordinsky MK, Zhang P Quiza C, Doshi U, Olsen EA. Efficacy and Safety of Once-Daily Minoxidil Foam 5\% Versus Twice-Daily Minoxidil Solution 2\% in Female Pattern Hair Loss: A Phase III, Randomized, Investigator-Blinded Study. J Drugs Dermatol. 2016;15(7):883-889.

84. Bazzano GS, Terezakis N, Galen W. Topical tretinoin for hair growth promotion. J Am Acad Dermatol. 1986;15(4 Pt 2):880-883, 890-893.

85. Shin HS, Won CH, Lee SH, Kwon OS, Kim KH, Eun HC. Efficacy of 5\% minoxidil versus combined $5 \%$ minoxidil and $0.01 \%$ tretinoin for male pattern hair loss: A randomized, double-blind, comparative clinical trial. Am J Clin Dermatol. 2007;8:285-290.

86. Dallob AL, Sadick NS, Unger W, Lipert S, Geissler LA, Gregoire SL, et al The effect of finasteride, a 5 alpha-reductase inhibitor, on scalp skin testosterone and dihydrotestosterone concentrations in patients with male pattern baldness. J Clin Endocrinol Metab. 1994;79(3):703-706.

87. Kelly Y, Blanco A, Tosti A. Androgenetic Alopecia: An Update of Treatment Options. Drugs. 2016;76(14):1349-1364. doi: 10.1007/ s40265-016-0629-5

88. Mella JM, Perret MC, Manzotti M, Catalano HN, Guyatt G. Efficacy and safety of finasteride therapy for androgenetic alopecia: a systematic review. Arch Dermatol. 2010;146:1141-1150. doi: 10.1001/ archdermatol.2010.256

89. Thai KE, Sinclair RD. Finasteride for female androgenetic alopecia. Br J Dermatol. 2002;147(4):812-813. DOI: 10.1046/j.13652133.2002.49084.x

90. Trüeb RM. Finasteride treatment of patterned hair loss in normoandrogenic postmenopausal women. Dermatology. 2004;209(3):202-207.

91. Iorizzo M, Vincenzi C, Voudouris S, Piraccini BM, Tosti A. Finasteride treatment of female pattern hair loss. Arch Dermatol. 2006;142(3):298302.

92. Price VH, Roberts JL, Hordinsky M, Olsen EA, Savin R, Bergfeld W, et al. Lack of efficacy of finasteride in post- menopausal women with androgenetic alopecia. J Am Acad Dermatol. 2000;43(5 Pt 1):768-776.

93. Whiting DA, Waldstreicher J, Sanchez M, Kaufman KD. Measuring reversal of hair miniaturization in androgenetic alopecia by follicular counts in horizontal sections of serial scalp biopsies: results of finasteride $1 \mathrm{mg}$ treatment of men and postmenopausal women. J Investig Dermatol Symp Proc. 1999;4(3):282-284.

94. Eun HC, Kwon OS, Yeon JH, Shin HS, Kim BY, Ro BI, et al. Efficacy, safety, and tolerability of dutasteride $0.5 \mathrm{mg}$ once daily in male patients with male pattern hair loss: a randomized, double-blind, placebocontrolled, phase III study. J Am Acad Dermatol. 2010;63(2):252-258. doi: $10.1016 /$ j.jaad.2009.09.018

95. Stough D. Dutasteride improves male pattern hair loss in a randomized study in identical twins. J Cosmet Dermatol. 2007;6(1):9-13.

96. Tsunemi Y, Irisawa R, Yoshiie H, Brotherton B, Ito H, Tsuboi R, et al. Long-term safety and efficacy of dutasteride in the treatment of male patients with androgenetic alopecia. J Dermatol. 2016;43(9):10511058. doi: $10.1111 / 1346-8138.13310$

97. Olsen EA, Hordinsky M, Whiting D, Stough D, Hobbs S, Ellis ML, et al. The importance of dual 5alpha-reductase inhibition in the treatment of male pattern hair loss: results of a randomized placebo-controlled study of dutasteride versus finasteride. J Am Acad Dermatol. 2006;55(6):1014-1023

98. Boersma IH, Oranje AP, Grimalt R, Iorizzo M, Piraccini BM, Verdonschot EH. The effectiveness of finasteride and dutasteride used for 3 years in women with androgenetic alopecia. Indian J Dermatol Venereol Leprol. 2014;80(6):521-525. doi: 10.4103/0378-6323.144162

99. Coneac A, Muresan A, Orasan MS. Antiandrogenic Therapy with Ciproterone Acetate in Female Patients Who Suffer from Both Androgenetic Alopecia and Acne Vulgaris. Clujul Med. 2014;87(4):226234. doi: $10.15386 /$ cjmed-386

100.Aizawa H, Niimura M. Adrenal androgen abnormalities in women with late onset and persistent acne. Arch Dermatol Res. 1993;284(8):451455 .

101.Martín-Hernández T, Jorquera E, Torres A. Efficacy of flutamide and cyproterone acetate in the treatment of hirsutism associated with polycystic ovary syndro006De. Actas Dermosifiliogr. 1995;86:327334.

102.Alves R, Grimalt R. A randomized placebo-controlled, double-blind, half-head study to assess the efficacy of platelet-rich plasma on the treatment of androgenetic alopecia. Dermatol Surg. 2016;42(4):491497. doi: 10.1097/DSS.0000000000000665

103.Trink A, Sorbellini E, Bezzola P, Rodella L, Rezzani R, Ramot Y, et al. A randomized, double-blind, placebo- and active-controlled, half-head study to evaluate the effects of platelet-rich plasma on alopecia areata. Br J Dermatol. 2013;169(3):690-694. doi: 10.1111/bjd.12397

104.Caserini M, Radicioni M, Leuratti C, Terragni E, Iorizzo M, Palmieri R. Effects of a novel finasteride $0.25 \%$ topical solution on scalp and serum dihydrotestosterone in healthy men with androgenetic alopecia. Int J 
Clin Pharmacol Ther. 2016;54(1):19-27. doi: 10.5414/CP202467

105.Hajheydari Z, Akbari J, Saeedi M, Shokoohi L. Comparing the therapeutic effects of finasteride gel and tablet in treatment of the androgenetic alopecia. Indian J Derma-tol Venereol Leprol. 2009;75(1):47-51.

106.Tanglertsampan C. Efficacy and safety of 3\% minoxidil versus combined 3\% minoxidil $/ 0.1 \%$ finasteride in male pattern hair loss: A randomized, double-blind, comparative study. J Med Assoc Thai. 2012;95(10):1312-1316.

107.Chandrashekar BS, Nandhini T, Vasanth V, Sriram R, Navale S. Topical minoxidil fortified with finasteride: An account of maintenance of hair density after replacing oral finasteride. Indian Dermatol Online J. 2015;6(1):17-20. doi: 10.4103/2229-5178.148925

108.Moftah N, Abd-Elaziz G, Ahmed N, Hamed Y, Ghannam B, Ibrahim M. Mesotherapy using dutasteride-containing preparation in treatment of female pattern hair loss: pho- tographic, morphometric and ultrustructural evaluation. J Eur Acad Dermatol Venere- ol. 2013;27(6):686-693. doi: 10.1111/j.1468-3083.2012.04535.x

109.Huang YY, Chen ACH, Carroll JD, Hamblin MR. Biphasic dose response in low level light therapy. Dose Response 2009;7(4):358-383. doi: 10.2203/dose-response.09-027.Hamblin

110.Gupta AK, Foley KA. A Critical Assessment of the Evidence for LowLevel Laser Therapy in the Treatment of Hair Loss. Dermatol Surg. 2017;43(2):188-197. doi: 10.1097/DSS.0000000000000904

111.Avci P, Gupta GK, Clark J, Wikonkal N, Hamblin MR. Low-level laser (light) therapy (LLLT) for treatment of hair loss. Lasers Surg Med. 2014;46(2):144-151. doi: 10.1002/lsm.22170

112.Wikramanayake TC, Rodriguez R, Choudhary S, Mauro LM, Nouri $\mathrm{K}$, Schachner LA, et al. Effects of the Lexington LaserComb on hair regrowth in the $\mathrm{C} 3 \mathrm{H} / \mathrm{HeJ}$ mouse model of alopecia areata. Lasers Med Sci. 2012; 27(2):431-436. doi: 10.1007/s10103-011-0953-7

113.Leavitt M, Charles G, Heyman E, Michaels D. HairMax LaserComb laser phototherapy device in the treatment of male androgenetic alopecia: $\mathrm{A}$ randomized, double-blind, sham device-controlled, multicentre trial. Clin Drug Investig. 2009;29(5):283-292. doi: 10.2165/00044011200929050-00001

114.Afifi L, Maranda EL, Zarei M, Delcanto GM, Falto-Aizpurua L, Kluijfhout WP et al. Low-level laser therapy as a treatment for androgenetic alopecia. Lasers Surg Med. 2017;49(1):27-39. doi: 10.1002/lsm.22512

115.Avram MR, Rogers NE. The use of low-level light for hair growth: part I. J Cosmet Laser Ther. 2009;11(2):110-117. doi: $10.1080 / 14764170902842531$

116.Jimenez JJ, Wikramanayake TC, Bergfeld W, Hordinsky M, Hickman JG, Hamblin MR, et al. Efficacy and safety of a low-level laser device in the treatment of male and female pattern hair loss: a multicenter, randomized, sham device-controlled, double-blind study. Am J Clin Dermatol. 2014;15(2):115-127. doi: 10.1007/s40257-013-0060-6

117.Kim H, Choi JW, Kim JY, Shin JW, Lee SJ, Huh CH. Low-level light therapy for androgenetic alopecia: a 24-week, randomized, doubleblind, sham device-controlled multicenter trial. Dermatol Surg 2013;39(8):1177-1183. doi: 10.1111/dsu.12200

118.Ahouansou S, Le Toumelin P, Crickx B, Descamps V. Association of androgenetic alopecia and hypertension. Eur J Dermatol. 2007;17(3):220-222.

119.Matilainen V, Koskela P, Keinänen-Kiukaanniemi S. Early androgenetic alopecia as a marker of insulin resistance. Lancet 2000;356(9236):1165-1166.

120.Sharma L, Dubey A, Gupta PR, Agrawal A. Androgenetic alopecia and risk of coronary artery disease. Indian Dermatol Online J. 2013;4(4):283-287. doi: 10.4103/2229-5178.120638

121.Arias-Santiago S, Gutiérrez-Salmerón MT, Castellote-Caballero L, Buendía-Eisman A, Naranjo-Sintes R. Androgenetic alopecia and cardiovascular risk factors in men and women: a comparative study. J Am Acad Dermatol. 2010;63(3):420-429. doi: 10.1016/j. jaad.2009.10.018 